\title{
A highly curable lymphoma occurs preferentially in the proximal tibia of young patients
}

\author{
M Kristina Subik 1,7,8, Megan M Herr ${ }^{2,8}$, Robert E Hutchison ${ }^{3}$, Jennifer Kelly ${ }^{4}$, \\ Wakenda K Tyler ${ }^{5}$, Mihai Merzianu ${ }^{6}$ and W Richard Burack ${ }^{1}$
}

${ }^{1}$ Department of Pathology, University of Rochester Medical Center, Rochester, NY, USA; ${ }^{2}$ Department of Community and Preventive Medicine, University of Rochester Medical Center, Rochester, NY, USA;

${ }^{3}$ Department of Pathology, SUNY Upstate Medical University, Syracuse, NY, USA; ${ }^{4}$ Department of Medicine, University of Rochester Medical Center, Rochester, NY, USA; ${ }^{5}$ Department of Orthopedics, University of Rochester Medical Center, Rochester, NY, USA and ${ }^{6}$ Department of Pathology, Roswell Park Cancer Institute, Buffalo, NY, USA

The presentation of two 19-year-old male subjects with stage I non-Hodgkin lymphoma in the proximal tibia prompted an extensive review of institutional and national databases to assess whether there is any statistical evidence that these reflected a previously overlooked syndromic pattern of presentation. The institutional records of a single institution were reviewed for presentation of non-Hodgkin lymphoma in the bone. The records of two additional institutions were reviewed for all reports of non-Hodgkin lymphoma in the tibia. Analysis was performed on data from Surveillance, Epidemiology, and End Results (SEER) dichotomized to bone presentation in the lower extremity versus other bones. Institutional databases included 20 patients with tibial presentation of lymphoma with a median age of 22.5 years (versus 42 for all bone lymphomas; $P<0.001$ ). Eighteen out of twenty patients had diffuse large B-cell lymphoma, and all patients aged $\leq \mathbf{4 0}$ achieved remission and apparent cure. Distinctive and unusual features were a tendency for bilateral involvement of the tibia and sclerotic changes on X-ray. SEER data included 808 cases of bone lymphoma; the fraction of cases presenting in the lower extremity versus other bone sites is higher at ages $\leq 40$ years $(38 \%$ versus $19 \%$; $\boldsymbol{P}<0.0001)$. Presentation in the lower extremity, as compared with other bone sites, confers $97 \%$ overall survival in patients aged $\leq \mathbf{4 0}$ (versus $\mathbf{8 2} \% ; P=0.01$ ). This survival effect was independent of stage. In contrast, no significant difference in overall survival was identified for lower extremity versus non-lower extremity site for age $>40$. These data show a previously undescribed syndromic pattern of disease presentation: bone lymphoma in young patients is likely to present in the lower extremity-specifically the proximal tibia-has atypical sclerotic features on X-ray, is often bilateral, and has an excellent prognosis compared with bone lymphomas at other sites matched for stage and age.

Modern Pathology (2014) 27, 1430-1437; doi:10.1038/modpathol.2014.51; published online 18 April 2014

Keywords: bone lymphoma; epidemiology; non-Hodgkin lymphoma; tibia

Correspondence: WR Burack, MD, PhD, Department of Pathology and Laboratory Medicine, University of Rochester Medical Center, 601 Elmwood Avenue, Box 626, Rochester, NY 14642, USA.

E-mail: richard_burack@urmc.rochester.edu

${ }^{7}$ Current Address: Department of Pathology and Laboratory Medicine, Albany Medical Center, Albany NY, James P. Wilmot Cancer Center, University of Rochester Medical Center, Rochester, NY, USA.

${ }^{8} \mathrm{MH}$ and MKS contributed equally to this manuscript.

Received 19 November 2013; accepted 5 February 2014; published online 18 April 2014
Lymphoma of the bone is a rare malignancy, first suggested by Oberling in 1928 and further described by Parker and Jackson in a series on 'reticulum cell sarcoma of bone. ${ }^{1,2}$ Primary bone lymphoma, as originally defined by Ostrowski, is a lymphoma of bone without disease present elsewhere for at least 6 months after initial diagnosis, account for less than $1 \%$ of all malignant lymphomas, and occur at a median age of 46 years. ${ }^{2}$ The characteristics of bone lymphoma have been further defined by a number of case series: the most common locations of bone lymphoma are variously reported as the spine, the 
ischium, and long bones-particularly the femur; the most common presenting symptom is pain associated with swelling; the most common histology is diffuse large B-cell lymphoma, and the phenotype may be Germinal Center- or Activated B-Cell-like. ${ }^{1-10}$ The current treatment of primary bone lymphoma appears to typically be a combination of chemotherapy and radiotherapy. ${ }^{9}$

We encountered two male patients, both aged 19 years, whose chief complaint was knee pain and each had a biopsy of the proximal tibia that was diagnostic of a B-cell lymphoma. In both cases, the proximal tibia was preferentially involved. One patient had bilateral proximal tibia involvement by diffuse large B-cell lymphoma, not otherwise specified. The other had unilateral tibia involvement by a low-grade B-cell lymphoma (not further classifiable) that was treated with local radiation and recurred 17 months later in the contralateral tibia. X-rays of both patients' bone showed a sclerotic pattern. These cases prompted us to review all lymphomas with an initial diagnosis of lymphoma in the bone at one institution, to identify all patients with tibial lymphoma at two additional institutions, and to examine the association of age and relative incidence of lower limb bone lymphoma within a national cancer database.

\section{Materials and methods}

Correlation of the clinical and pathology records of the University of Rochester Medical Center from 2003 to 2011 identified all lymphomas in patients whose initial diagnosis was based on a bone biopsy (excluding iliac crest) directed at a radiographic lesion. The demographics, symptoms at presentation, radiologic findings, clinical stage, treatment, and follow-up were identified for the subset of bone lymphoma specimens for which the site was tibia in the pathology report (Table 1). The demographics and clinical stage were also obtained for the subset of bone lymphoma specimens for which the site was femur. Immunohistochemical stains were reviewed. Radiologic images of the cases at the index institution were reviewed. Reproducibility of findings was assessed by searching the pathology records of two other institutions for lymphomas diagnosed in the tibia; the latter searches were preformed without age restriction and without the stipulation that the specimen represent the patient's initial diagnosis.

The Surveillance, Epidemiology, and End Results (SEER) Program of the National Cancer Institute is a population-based national cancer database comprising data on incident cancer cases contributed from registries across the United States. SEER began collecting data from nine registries in 1973; currently, SEER includes data captured on incident cases from 17 participating registries, a catchment area representing $\sim 28 \%$ of the US population. ${ }^{11,12}$

In order to limit the influence of variability in referral and diagnosis patterns, data from the 2000 to
2009 SEER data set were used for this analysis; this data set comprised incident cancer cases captured in 17 SEER site registries. Inclusion in the analysis data set was limited to patients with a lymphoma diagnosis (ICDO3 codes 9590, 9591, 9650, 9663, 9670, 9671, 9673, 9675, 9680, 9684, 9687, 9690, 9691, 9695, 9698, 9699, 9702, 9714, 9727, 9728, 9729, 9920, and 9930; $n=129097)$ and bone as their primary site of disease (only included if site was C40.0, C40.1,C40.2, C40.3, C40.8, C40.9, C41.0, C41.1, C41.2, C41.3, C41.4, C41.8, C41.9; $n=1315) .{ }^{12}$ Patients diagnosed with plasma cell tumors (ICDO3 9730-9739) were excluded from this analysis $(n=923)$. Our final analysis data set included 808 lymphomas with bone involvement diagnosed from 2000 to 2009. Histology was grouped by ICDO3 codes into malignant lymphomas not otherwise specified, Hodgkin lymphomas, nonHodgkin lymphoma-mature T- and NK-cell lymphomas, non-Hodgkin lymphoma-precursor cell lymphoblastic lymphoma, myeloid leukemias, and non-Hodgkin lymphoma-mature B-cell lymphomas, which was further categorized into diffuse large B-cell lymphoma, not otherwise specified and other. The stage was captured according to the SEER collaborative staging algorithm.

Involvement of the tibia, specifically, is not captured with the ICDO3 site codes; therefore, patients with primary involvement of the long bones of the lower limb and associated joints (C40.2) were designated as the lower extremity cases and were compared with other bone lymphoma patients with the involvement of all other sites. From this point forward, patients with lymphoma involvement of any long bones of the lower limb and associated joints will be referred to as 'lower extremity' cases.

Descriptive analyses included presentation of case characteristics by frequency and percents, stratified by age, site of bone involvement (lower extremity versus other bone sites), and gender. Differences in age and stage of lymphoma at diagnosis by the site of bone involvement were analyzed using $\chi^{2}$ tests. Overall Survival was defined as the time from diagnosis to the date of death from any cause; patients who were still alive at the end of follow-up were censored as of 31 December 2009. Overall survival was estimated by standard Kaplan-Meier survival techniques. We compared overall survival between cases with lower extremity involvement and cases with lymphoma involvement of other bone sites using the log-rank test. A Cox proportional hazards model was used for multivariable analyses. Analyses were implemented using SAS software system (SAS Institute, Cary, NC, USA; Version 9.3).

\section{Results}

An institutional search identified all bone lymphoma specimens obtained from 2003 to 2011. Forty-nine cases of non-Hodgkin lymphoma with biopsy-proven 
Table 1 Subjects' clinical and pathologic characteristics

\begin{tabular}{|c|c|c|c|c|c|c|c|c|c|}
\hline & Sex & Age & Diagnosis & Phenotype & $X$-ray & Stage & Sites & Therapy & Follow-up \\
\hline 1 (Index) & M & 19,21 & $\begin{array}{l}\text { Low-grade B-cell; } \\
\text { centrocyte-like } \\
\text { cytology, diffuse }\end{array}$ & $\begin{array}{l}\text { + CD20/79a; clonal IGH, } \\
\text { PCR, - BCL6 }\end{array}$ & Sclerosis & IE & Bilateral proximal tibia & XRT & $\begin{array}{l}59 \text { Months NED (post } \\
\text { recurrence in opposite } \\
\text { tibia) }\end{array}$ \\
\hline 2 & M & 32 & DLBCL centroblastic & + CD20/79a, - CD10 & Sclerosis & IVB & $\begin{array}{l}\text { Proximal tibia, iliac, } \\
\text { sacrum, LNs }\end{array}$ & R-CHOP & 77 Months NED \\
\hline 3 & M & 17 & $\begin{array}{l}\text { Pre-B lymphoblastic } \\
\text { lymphoma }\end{array}$ & + CD79a, + TdT & Sclerosis & III-IV & $\begin{array}{l}\text { Tibia, femur, elbow, } \\
\text { mediastinum, LNs }\end{array}$ & Pediatric ALL protocol & 63 Months NED \\
\hline 4 & $\mathrm{~F}$ & 24 & DLBCL centroblastic & $\begin{array}{c}\text { + CD20/79a/10, + BCL6/kappa, } \\
\text { - BCL2, - MUM1 }\end{array}$ & $\begin{array}{l}\text { Sclerotic and } \\
\text { lytic }\end{array}$ & IV & $\begin{array}{l}\text { Bilateral proximal } \\
\text { tibia, LN }\end{array}$ & $\mathrm{R}-\mathrm{CHOP}+\mathrm{XRT}$ & 43 Months NED \\
\hline 5 & $\mathrm{M}$ & 38 & DLBCL necrotic & $+\mathrm{CD} 20$ & Sclerosis & IV & Tibia and LN & $\mathrm{R}-\mathrm{CHOP}+\mathrm{XRT}$ & 30 Months NED \\
\hline 6 (Index) & $\mathrm{M}$ & 19 & DLBCL centroblastic & + CD20, + lambda, - CD10 & $\begin{array}{l}\text { Sclerotic and } \\
\text { lytic }\end{array}$ & IVA & Bilateral proximal tibia & R-CHOP & 30 months NED \\
\hline 7 & $\mathrm{M}$ & 19 & DLBCL necrotic & $+\mathrm{CD} 20 / 79 \mathrm{a} / 10$ & Sclerosis & $\mathrm{IE}$ & Proximal tibia & $\mathrm{R}-\mathrm{CHOP}+\mathrm{XRT}$ & 129 Months NED \\
\hline 8 & $\mathrm{M}$ & 34 & DLBCL centroblastic & + CD20/79a, - CD45ro & Lytic cyst & IE & Proximal Tibia & CHOP + XRT & 78 Months NED \\
\hline 9 & $\mathrm{~F}$ & 13 & DLBCL & & NA & IE & Tibia & NA & NA \\
\hline 10 & M & 56 & DLBCL necrosis & $\begin{array}{c}+ \text { CD20/79a, + BCL2/6 } \\
- \text { TdT/CD34 }\end{array}$ & Lytic & IV & Bilateral tibia, clavicle & R-CHOP + auto SCT & $\begin{array}{l}20 \text { Months died of } \\
\text { disease at }\end{array}$ \\
\hline 11 & $\mathrm{~F}$ & 85 & $\begin{array}{l}\text { DLBCL with fibrosis } \\
\text { and necrosis }\end{array}$ & $\begin{array}{c}+ \text { CD20/10, + BCL6 } \\
- \text { BCL2 - CD3 }\end{array}$ & NA & $\mathrm{IE}$ & Tibia & $\mathrm{R}-\mathrm{CHOP}+\mathrm{XRT}$ & 72 Months NED \\
\hline 12 & $\mathrm{M}$ & 15 & $\begin{array}{l}\text { DLBCL with fibrosis } \\
\text { and necrosis }\end{array}$ & $\begin{array}{c}\text { + CD20, - CD30/15, } \\
-\mathrm{CD} 43 / 45 \mathrm{ra},-\mathrm{MPO} / \mathrm{Lys}\end{array}$ & Sclerosis & NA & Tibia and femur & NA & NA \\
\hline 13 & $\mathrm{M}$ & 28 & DLBCL & + CD20/45, - CD30/99 & NA & IE & Tibia & $\mathrm{CHOP}+\mathrm{XRT}$ & 74 Months NED \\
\hline 14 & $\mathrm{~F}$ & 21 & DLBCL & + CD20 & Sclerosis & IE & Tibia & $\mathrm{CHOP}+\mathrm{XRT}$ & 14 Months NED \\
\hline 15 & $\mathrm{~F}$ & 21 & DLBCL with fibrosis & $+\mathrm{CD} 20,-\mathrm{CD} 3,-\mathrm{CD} 45 \mathrm{RO}$ & NA & NA & Tibia and femur & NA & NA \\
\hline 16 & $\mathrm{M}$ & 19 & $\begin{array}{l}\text { DLBCL with dense } \\
\text { fibrosis }\end{array}$ & $+\mathrm{CD} 20 / 79 \mathrm{a},-\mathrm{TdT}$ & NA & $1 \mathrm{E}$ & Proximal tibia & R-CHOP + XRT & 86 Months NED \\
\hline 17 & $\mathrm{M}$ & 48 & DLBCL with fibrosis & + CD20, - BCL2, - cyclin D1 & NA & $1 \mathrm{E}$ & Proximal tibia & $\mathrm{R}-\mathrm{CHOP}+\mathrm{XRT}$ & 19 Months NED \\
\hline 18 & $\mathrm{M}$ & 31 & DLBCL & + CD 20 & NA & $1 \mathrm{E}$ & $\begin{array}{l}\text { Tibia predominantly } \\
\text { distal with proximal } \\
\text { extension }\end{array}$ & R-CHOP & 70 Months NED \\
\hline 19 & M & 20 & $\begin{array}{l}\text { DLBCL, } \\
\text { immunoblastic }\end{array}$ & $+\mathrm{CD} 20 / 10,+$ PAX5, + BCL6 & NA & $1 \mathrm{E}$ & Proximal tibia & R-CHOP & 60 Months NED \\
\hline 20 & $\mathrm{M}$ & 29 & DLBCL & $+\mathrm{CD} 20 / 45,-\mathrm{CD} 45 \mathrm{ro}$ & NA & NA & Proximal tibia & NA & NA \\
\hline
\end{tabular}

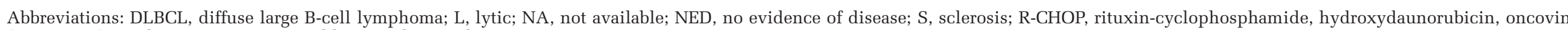
(vincristine), prednisone; XRT, external beam radiation therapy.

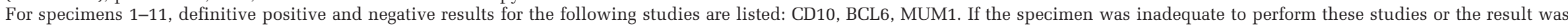
inconclusive, the phenotype is not listed. For specimens $12-20$, the phenotypes are as described in the original surgical pathology reports. 
initial presentation in the bone were identified at the index institution; these had a median age at presentation of 42 years (data not shown). Of these, 10 patients $(\sim 20 \%)$ had tibial lymphoma. These patients were significantly younger (median age of 21.5 years; $P<0.001$ ). In all of these 10 cases, review of the clinical data indicated that knee pain or swelling was the primary symptom. None of these specimens included any other involved sites, although subsequent imaging suggested the involvement of other bone sites and lymph nodes in several patients (Table 1); six fulfilled criteria for "primary bone lymphoma'.2 The remaining four cases showed predominant involvement of the tibia and clinically were thought most likely to represent primary tibial lymphoma. Eleven patients had initial presentation of lymphoma in the femur and these patients were strikingly older than those who presented with tibial disease (median age of $74 ; P<0.001$ ). Similar searches of bone lymphomas (without restrictions with regard to patient age or initial site of presentation) at two other institutions identified 10 additional tibial non-Hodgkin lymphoma cases; the median age was 24.5 years. Together, the 20 cases of tibial lymphoma had an age range of 13-85, median age of 22.5 years, and a male:female ratio of $3: 1$ (Table 1). With the exception of a 56-year-old patient, the available radiographs for all patients at the index institution showed sclerotic changes (Figure 1). No radiographic features or case histories were particularly suggestive of antecedent OsgoodSchlatter disease.

All tumors were B-cell lymphomas; all but two had diffuse large B-cell lymphoma histology and were positive for CD20 and/or CD79a. One patient (Table 1, patient 1) showed a low-grade histology composed of monomorphic small lymphocytes; this material was the subject of extensive extramural consultation that corroborated the diagnosis. This latter lymphoma recurred after 17 months in the contralateral tibia. One patient with atypically widespread disease had precursor B-cell lymphoblastic leukemia/lymphoma (3 in Table 1). The cases often had a low stage and an overall good prognosis. Of the 17 cases where stage was available, 10 cases were limited to the tibia (stage IE). Bilateral tibia involvement was identified in 4 of the 10 index institution cases. For cases where therapy was known, most were treated with combined modalities of chemotherapy and radiation. Of the nine cases at the index institution with follow-up (average 56.4 months), one recurred in the contralateral tibia, one died of his lymphoma (56 years old at presentation), and seven had no recurrence of disease.

The SEER database (2000-2009) includes 808 cases of lymphoma with bone presentation. As the SEER database does not specify bone site beyond lower extremity, we used this subgroup as a surrogate for the proximal tibia. The most common histology for the lymphomas with bone involvement was diffuse large B-cell lymphoma, not otherwise specified, regardless of the site of involvement. No difference was apparent in the median ages for presentation in the lower extremity (187 cases, median age 57) versus all other bone sites (621 cases, median age 63).

In younger patients, a significantly larger fraction of bone lymphoma is present in the lower extremity bones compared with other bones $(38 \%$ for $\leq 40$ versus $19 \%$ for $>40$ years, $P<0.0001$; Table 2 ). This difference is most striking for male patients aged 1030 years (Figures $2 \mathrm{a}$ and $\mathrm{b}$ ). Overall, half (53.3\%) of bone lymphomas, regardless of age, were limited stage disease (Stage I/IE). A significantly greater fraction of lower extremity bone lymphomas was low stage compared with other sites regardless of age (Table 3).

Young patients with lower extremity bone presentation of non-Hodgkin lymphoma had a superior overall survival compared with young patients with other bone sites at presentation (Figure 3). As expected, survival was worse in patients over 40 years (Figure $3 \mathrm{~b}$ ) in comparison with patients aged $\leq 40$ (Figure 3a). More striking is the differential effect of site of bone involvement when stratified by age. Five-year overall survival in patients aged $\leq 40$ with lower extremity presentation was $97 \%$ versus $82 \%$ in non-lower extremity presentation (Figure 3a). The difference in overall survival by the site of bone involvement among patients $\leq 40$ is highly significant $(P=0.0086)$. After controlling for stage, the effect of lower extremity presentation on overall survival remains statistically significant $(P=0.0485)$. Among patients aged $>40$ (Figure 3b), 2-year overall survival among those with lower extremity involvement was $73 \%$ versus $68 \%$ in non-lower extremity bone involvement and 5-year overall survival was $68 \%$ versus $57 \%$ (log-rank $P=0.15)$. As the curves repeatedly cross and do not separate until 12 months, site may have no real effect on survival in those aged $>40$.

\section{Discussion}

Our data reveal a syndromic pattern of presentation of lymphoma that occurs specifically in the proximal tibia of young people ( $\leq 40$ years old) presenting with knee pain and/or swelling, is frequently bilateral, and shows sclerotic changes on imaging. Epidemiologic data indicate that lymphoma of lower extremity bones has excellent prognosis compared with bone non-Hodgkin lymphoma presenting in young patients at other sites. Furthermore, in our patients the lymphoma was often highly restricted to the proximal tibia and showed a profound tropism for this site: of 10 patients at the index institution, 6 patients had lymphoma solely in the proximal tibia as the only bone site and 4 patients demonstrated bilateral proximal tibial involvement with relative sparing of other bone sites. Our 

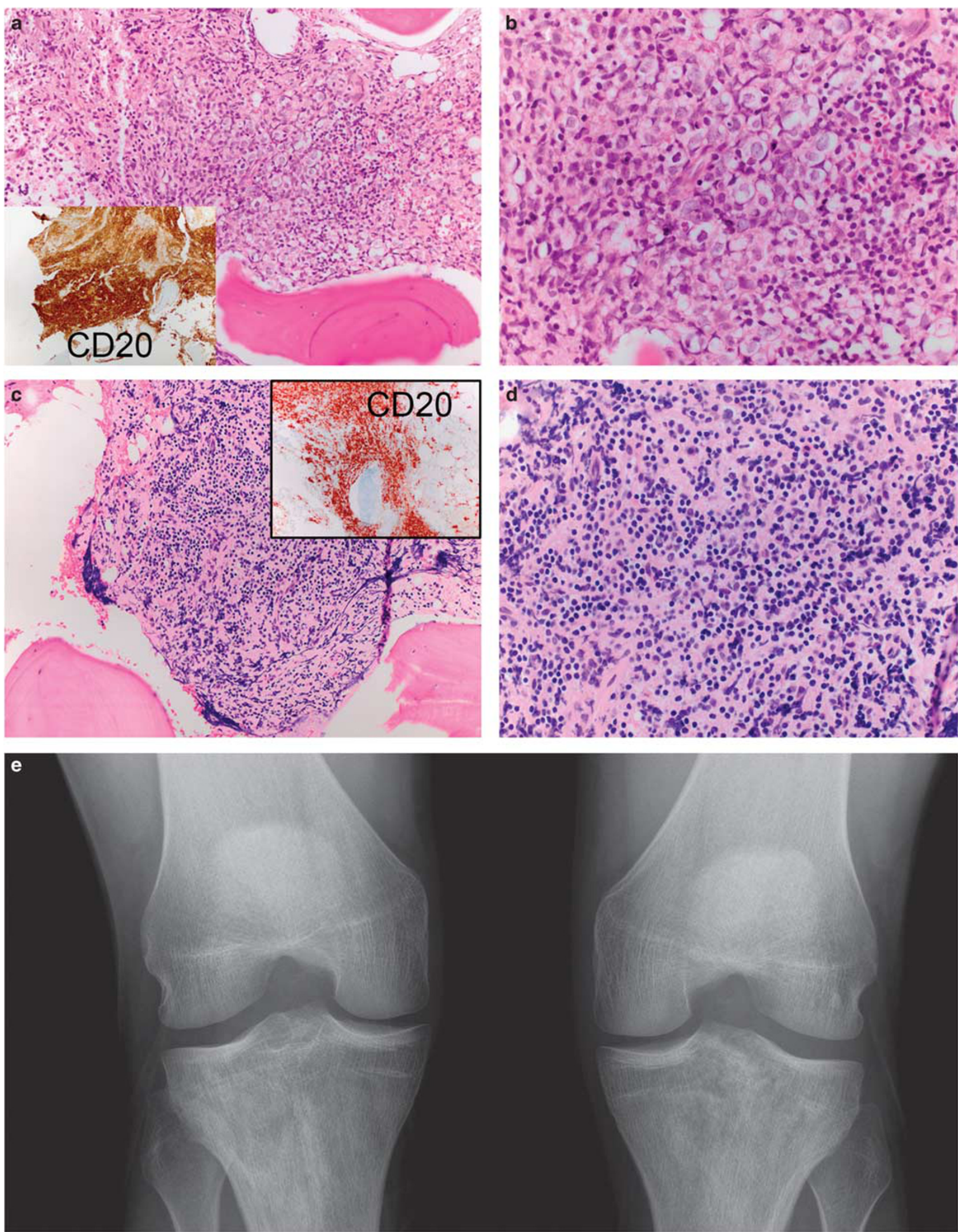

Figure $1 \mathrm{H} \& \mathrm{E}$ and CD20 stain of for index patient 6 (original magnification: (a) $\times 200,(\mathbf{b}) \times 400$ ). H\&E and CD20 stain of for index patient 1 (original magnification: $(\mathbf{c}) \times 200,(\mathbf{d}) \times 400)$. X-ray of patient 6 at presentation shows bilateral sclerosis of the proximal tibias $(\mathbf{e})$. The decreased and variable radiolucency of the tibial epiphyses and metaphyses is best appreciated by comparison to homogenous lucency of the femurs and fibulas. 
Table 2 Comparing age of lymphoma diagnosis by site of bone involvement; SEER 17 registry data, 2000-2009

\begin{tabular}{|c|c|c|}
\hline & \multicolumn{2}{|c|}{ Age at diagnosis count ( $\%$ of column) } \\
\hline & $\leq 40$ & $>40$ \\
\hline Lower extremity & $66(38 \%)$ & $121(19 \%)$ \\
\hline Other bone & $107(62 \%)$ & $514(81 \%)$ \\
\hline Total & 173 & 635 \\
\hline
\end{tabular}

Abbreviation: SEER, Surveillance, Epidemiology, and End Results. $P<0.0001 \chi^{2}$.
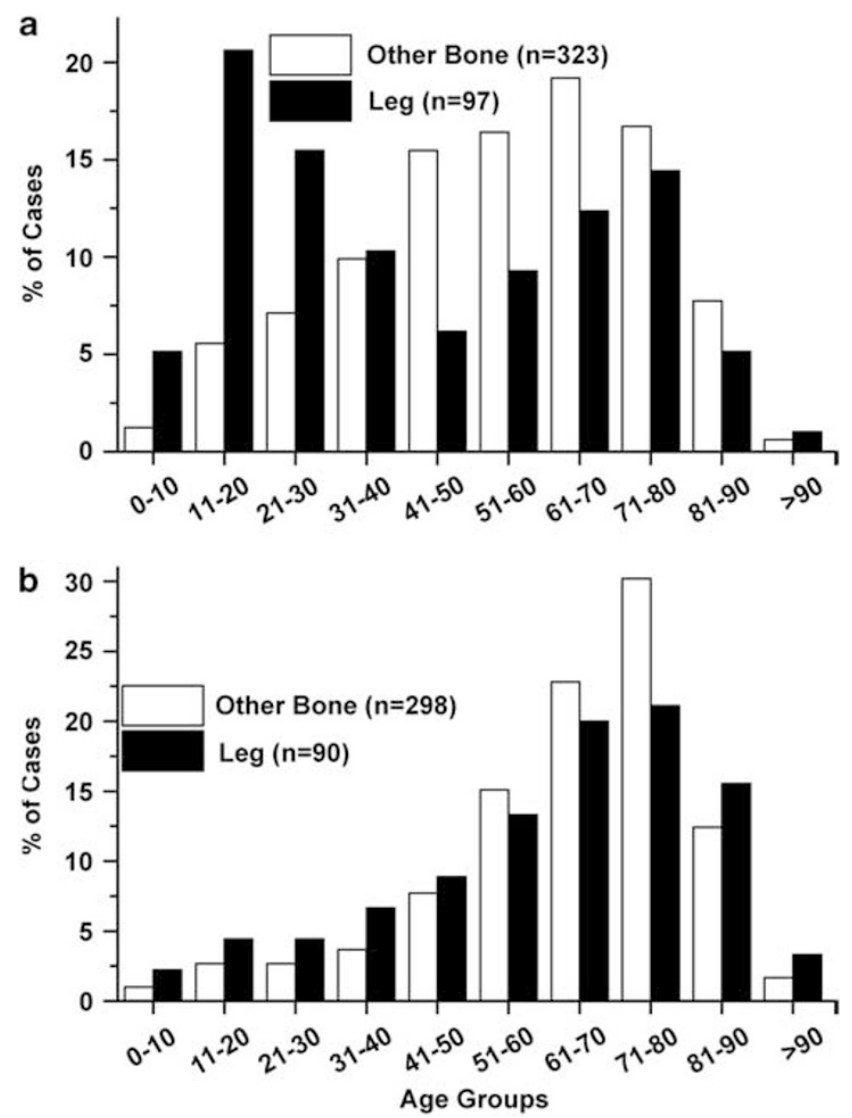

Figure 2 Percent of lymphoma cases with bone involvement by sex (male/female (a and $\mathbf{b}$ ), age group, and stratified by the site of bone involvement. Filled bars: lower extremity. Open bars: all other bone sites. (SEER 17 registry data, 2000-2009).

institutional data show a striking bias toward tibial rather than femoral presentation in young patients (25 versus 74 years median age of presentation). Strikingly, the youngest patient (18 years old) with femoral presentation of lymphoma at this institution had disease characterized by the surgeon as 'knee and distal femur', suggesting a similarity to the presentations seen in the proximal tibia.

Although the SEER database does not include localization specifically to the proximal tibia, the
Table 3 Comparing stage of lymphoma diagnosis by site of bone involvement; SEER 17 registry data, 2000-2009

\begin{tabular}{|c|c|c|c|c|}
\hline & \multicolumn{2}{|c|}{ Age $\leq 40$} & \multicolumn{2}{|c|}{ Age $>40$} \\
\hline & \multicolumn{2}{|c|}{$\mathrm{n}=167$} & \multicolumn{2}{|c|}{$\mathrm{n}=598$} \\
\hline & Other bone & L. Ext. & Other bone & L. Ext. \\
\hline Stage I/IE & $45(44 \%)$ & $49(75 \%)$ & $262(54 \%)$ & $75(65 \%)$ \\
\hline Stage II, III, IV & $57(56 \%)$ & $16(25 \%)$ & $221(46 \%)$ & $40(35 \%)$ \\
\hline$\chi^{2} P$-value & \multicolumn{2}{|c|}{0.0001} & \multicolumn{2}{|c|}{0.033} \\
\hline
\end{tabular}

Abbreviations: L. Ext., lower extension; SEER, Surveillance, Epidemiology, and End Results.
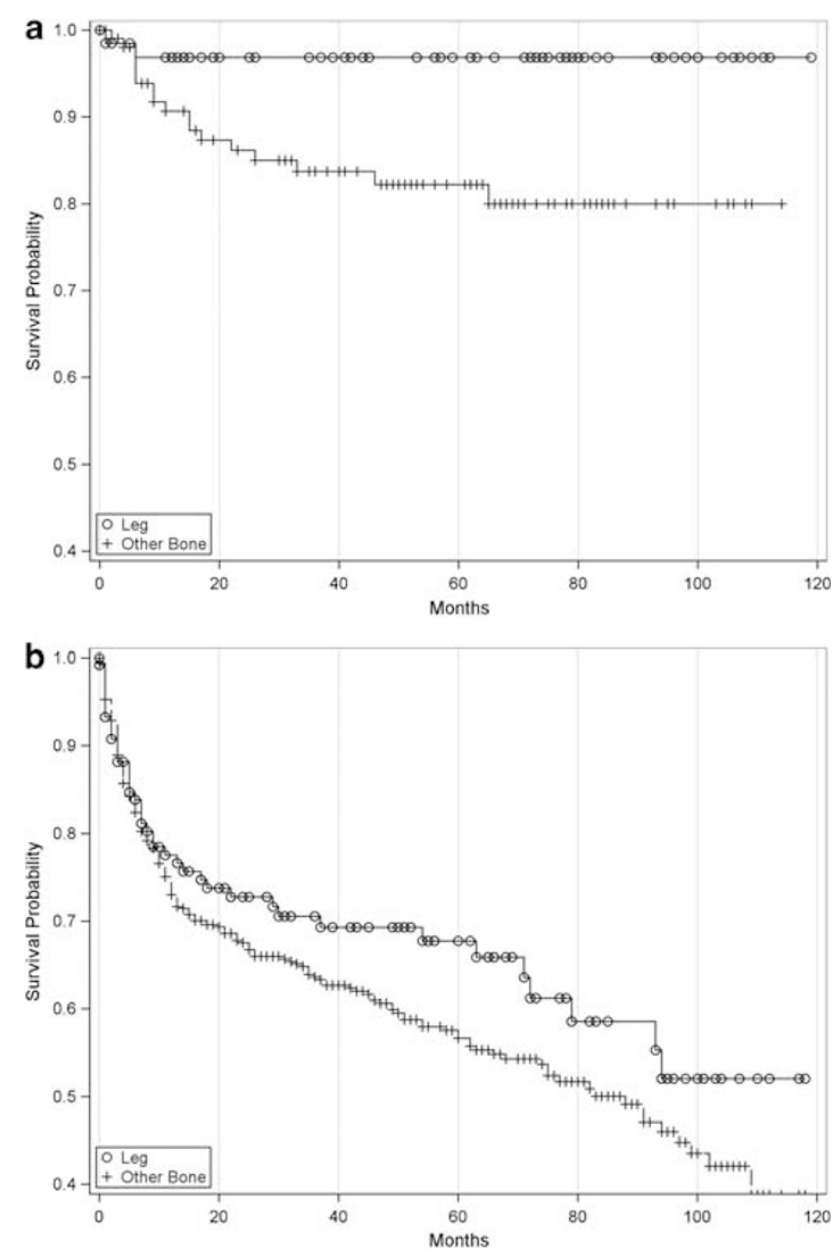

Figure 3 Kaplan-Meier curves for bone lymphoma, stratified by the site of involvement. (a) Overall survival in patients aged 40 and younger; (b) Overall survival in patients older than 40 . Circles: lower extremity. Cross: all other bone sites. (SEER, 2000-2009; median follow-up of 48 months).

data on the lower extremity corroborate and extend our institutional findings. Most importantly, cases of lower extremity lymphoma in young 
patients had significantly better overall survival in comparison to lymphomas of non-lower extremity bone sites in young patients. Although lower extremity presentation tended to be associated with a lower stage, low stage did not fully account for the improved overall survival; site of bone involvement remained statistically significant after adjustment for stage in the multivariate Cox proportional hazards model.

A sclerotic radiographic pattern was identified in all seven cases at the index institution in patients aged $\leq 40$ for whom imaging was available. Overall, 9/11 patients with available radiologic information had either purely sclerotic or mixed sclerotic lesion, and only two had a purely lytic lesion. This finding is in contrast with the typical lytic appearance of Non-Hodgkin lymphomas of the bone, which is either permeative or moth-eaten, with bone destruction as a significant feature. ${ }^{10,13,14}$ A predominately sclerotic image, whereas more often seen in classical Hodgkin lymphoma of the bone, is described in just $2 \%$ of bone non-Hodgkin lymphoma. ${ }^{15}$ Therefore, radiographic sclerosis may be a diagnostic clue for non-Hodgkin lymphoma presenting in the proximal tibia.

Whereas a range of common studies was attempted (eg, immunohistochemical studies for CD10, MUM1, BCL2, BCL6, EBV-LMP, and Ki-67, as well as in situ hybridization for EBER), no shared histologic, immunophenotypic, or genetic features that further characterized these B-cell tumors were identified. The specimens were in general small and crushed, and the decalcification performed on most hindered any PCR-based analyses. Bone lymphomas are often difficult to diagnose and classify, and the osteoblastic/ sclerotic nature of these tumors makes them particularly prone to crush artifact and limited sample size. In fact, several of the patients required repeat procedures to obtain sufficient material for the final diagnosis.

This syndromic pattern of presentation of lymphoma may have escaped notice in prior studies of 'primary bone lymphoma' because many of our patients (eg, patients 2-5) would have been excluded from those series, as there was lymph node involvement at the time of presentation. Furthermore, the patient ages straddled the cutoff between adult and pediatric series; our two index cases were both seen in adult clinics and were not enrolled on pediatric trials. Still, the SEER data show that the highest incidence of lower extremity bone lymphomas for male patients is in the second decade (see Figure 2). Our review of the literature identified nine publications describing seven case series of pediatric bone lymphomas ${ }^{16-24}$ (the two largest series are each reported in two parts, with a publication describing a follow-up time point ${ }^{21,22}$ or the clinical and histologic data described separately ${ }^{18,24}$ ). These series document that pediatric primary bone lymphoma commonly presents in the lower limb. Whereas the femur may be a more common site of lymphoma than the tibia, it is unclear whether the femoral presentation is associated with the same syndromic pattern of presentation involving a complaint of knee pain with sclerosis on bone X-ray. Regardless, one of these series of pediatric primary bone lymphomas showed a striking similarity to the series we describe here; Zhao et $a l^{24}$ describe a series of 10 pediatric patients with 'primary bone lymphoma', all male, four with tibial presentation, and one of which was bilateral.

The bilateral presentation in the proximal tibias with sparing of other sites has also been described by others. For example, two recent case reports both show striking images of bilateral proximal tibial lymphoma, although both in older male patients. ${ }^{25,26}$

Several non-Hodgkin lymphoma subtypes with site-specific biology, prognostic and treatment characteristics, and even distinctive molecular features have been described and incorporated into the World Health Organization's (WHO's) classification of lymphoid tumors. ${ }^{27}$ The site-specific pathogenesis of a subset of these is thought to be dependent on chronic, local inflammation, the most common of which are the various forms of mucosal associated lymphoid tissue lymphoma. The WHO also recognizes 'diffuse large B-cell lymphoma associated with chronic inflammation', the prototypical form of which occurs in male patients in the seventh decade and specifically in the pleural cavity; it has also been described to be associated with inflammation around metal implants in the femur. ${ }^{28}$ A small case series of bone lymphomas putatively associated with trauma has been reported..$^{29}$ Our reviews of the patients' medical records did not suggest any obvious etiologies for the cases of proximal tibial non-Hodgkin lymphoma; however, one possible explanation relates to the increased athletic activities of this age group that might result in repetitive microtrauma and subsequent inflammation of the proximal tibia. Whereas evidence of EBV infection is typically found in cases of 'diffuse large B-cell lymphoma associated with chronic inflammation', we were unable to detect EBV in any of the tumors from patients $<40$ years old in this series.

In sum, we describe a strong association between proximal tibial lymphoma (often bilateral), young age, sclerotic lesions on X-ray, and excellent prognosis, associations that are reinforced by analyses of the SEER database. Because of the uncommon nature of these tumors, an increased awareness of the possibility of this unusual lymphoma in young patients is essential, as ample diagnostic materials are required for diagnostic studies, including immunohistochemical and molecular studies, and prognosis may vary significantly by the site of involvement. In addition, this syndromic pattern of presentation suggests intriguing hypotheses regarding the relationship between microtrauma and the development of lymphoma. 


\section{Acknowledgments}

This publication was supported by a grant from the Upstate New York Translational Research Network to WRB, administered through the University of Rochester CTSA under award number UL1 RR024160 from the National Center for Research Resources and the National Center for Advancing Translational Sciences of the National Institutes of Health. The content is solely the responsibility of the authors and does not necessarily represent the official views of the National Institutes of Health.

\section{Disclosure/conflict of interest}

The authors declare no conflict of interest.

\section{References}

1 Krishnan Unni K, Inwards CY, Bridge JA, et al. Malignant lymphoma. In: Steven S (ed). AFIP Atlas of Tumor Pathology: Tumors of the Bones and Joints. ARP Press: Silver Spring, MD, 2005, pp 231-248.

2 Ostrowski ML, Unni KK, Banks PM, et al. Malignant lymphoma of bone. Cancer 1986;58:2646-2655.

3 Alencar A, Pitcher D, Byrne G, et al. Primary bone lymphoma-the University of Miami experience. Leuk Lymphoma 2010;51:39-49.

4 Beal K, Allen L, Yahalom J. Primary bone lymphoma: treatment results and prognostic factors with long-term follow-up of 82 patients. Cancer 2006;106:2652-2656.

5 Bhagavathi S, Micale MA, Les K, et al. Primary bone diffuse large B-cell lymphoma: clinicopathologic study of 21 cases and review of literature. Am J Surg Pathol 2009;33:1463-1469.

6 de Leval L, Braaten KM, Ancukiewicz M, et al. Diffuse large B-cell lymphoma of bone: an analysis of differentiation-associated antigens with clinical correlation. Am J Surg Pathol 2003;27:1269-1277.

7 Gianelli U, Patriarca C, Moro A, et al. Lymphomas of the bone: a pathological and clinical study of 54 cases. Int J Surg Pathol 2002;10:257-266.

8 Lima FP, Bousquet M, Gomez-Brouchet A, et al. Primary diffuse large B-cell lymphoma of bone displays preferential rearrangements of the c-MYC or BCL2 gene. Am J Clin Pathol 2008;129:723-726.

9 Ramadan KM, Shenkier T, Sehn LH, et al. A clinicopathological retrospective study of 131 patients with primary bone lymphoma: a population-based study of successively treated cohorts from the British Columbia Cancer Agency. Ann Oncol 2007;18:129-135.

10 Unni KK, Dahlin DC. Dahlin's Bone Tumors: General Aspects and Data on 11087 Cases. Lippincott-Raven: Philadelphia, 1996.

11 Harlan LC, Hankey BF. The surveillance, epidemiology, and end-results program database as a resource for conducting descriptive epidemiologic and clinical studies. J Clin Oncol 2003;21:2232-2233.

12 Surveillance, Epidemiology and End Results (SEER) Program, National Cancer Institute. www.seer.cancer. gov (Research Data 1973-2008) Released April 2011, based on the November 2010 submission. www.seer. cancer.gov.

13 Barbieri E, Cammelli S, Mauro F, et al. Primary nonHodgkin's lymphoma of the bone: treatment and analysis of prognostic factors for Stage I and Stage II. Int J Radiat Oncol Biol Phys 2004;59:760-764.

14 Tong MYT, Wu WC, Lam JJ, et al. Primary NonHodgkin's lymphoma of bone: a rare cause of lytic bone lesion. J HK Coll Radiol 2004;7:24-30.

15 O’Neill J, Finlay K, Jurriaans E, et al. Radiological manifestations of skeletal lymphoma. Curr Probl Diagn Radiol 2009;38:228-236.

16 Coppes MJ, Patte C, Couanet D, et al. Childhood malignant lymphoma of bone. Med Pediatr Oncol 1991;19:22-27.

17 Furman WL, Fitch S, Hustu HO, et al. Primary lymphoma of bone in children. J Clin Oncol 1989;7: 1275-1280.

18 Glotzbecker MP, Kersun LS, Choi JK, et al. Primary non-Hodgkin's lymphoma of bone in children. J Bone Joint Surg Am 2006;88:583-594.

19 Howat AJ, Thomas $\mathrm{H}$, Waters KD, et al. Malignant lymphoma of bone in children. Cancer 1987;59: 335-339.

20 Loeffler JS, Tarbell NJ, Kozakewich H, et al. Primary lymphoma of bone in children: analysis of treatment results with adriamycin, prednisone, Oncovin (APO), and local radiation therapy. J Clin Oncol 1986;4: 496-501.

21 Lones MA, Perkins SL, Sposto R, et al. Non-Hodgkin's lymphoma arising in bone in children and adolescents is associated with an excellent outcome: a Children's Cancer Group report. J Clin Oncol 2002;20:2293-2301.

22 Suryanarayan K, Shuster JJ, Donaldson SS, et al. Treatment of localized primary non-Hodgkin's lymphoma of bone in children: a Pediatric Oncology Group study. J Clin Oncol 1999;17:456-459.

23 Wollner N, Lane JM, Marcove RC, et al. Primary skeletal non-Hodgkin's lymphoma in the pediatric age group. Med Pediatr Oncol 1992;20:506-513.

24 Zhao XF, Young KH, Frank D, et al. Pediatric primary bone lymphoma-diffuse large B-cell lymphoma: morphologic and immunohistochemical characteristics of 10 cases. Am J Clin Pathol 2007;127:47-54.

25 Giardino AA, Shinagare AB, Shinagare SA, et al. Primary bone lymphoma involving bilateral tibia. Am J Hematol 2012;87:924-925.

26 Wong CL, Mansberg R, Yosufzai M. Symmetric bony involvement of the lower extremities with lymphoma demonstrated on gallium scintigraphy. Clin Nucl Med. 2005;30:353-355.

27 Jaffe ES, Harris NL, Stein H, et al. Introduction and overview of the classification of the lymphoid neoplasms, In: Swerdlow SH, Campo E, Harris NL, Jaffe ES, Pileri SA, Stein H, Thiele J, Vardiman JW(eds). WHO Classification of Tumours of Haematopoietic and Lymphoid Tissues. IARC: Lyon; 2008, pp 158-199.

28 Cheuk W, Chan AC, Chan JK, et al. Metallic implantassociated lymphoma: a distinct subgroup of large B-cell lymphoma related to pyothorax-associated lymphoma? Am J Surg Pathol 2005;29:832-836.

29 Stein ME, Lewis DC, Gershuny AR, et al. Trauma as an etiologic factor of primary bone lymphoma: a report of 4 cases. J BUON 2003;8:163-166. 